\title{
Concentration of unconventional methane resources using microporous membranes: process assessment and scale-up
}

\author{
Pablo Marín ${ }^{1,2}$, Zhuxian Yang ${ }^{2}$, Yongde Xia², Salvador Ordóñez ${ }^{1, *}$ \\ ${ }^{1}$ Catalysis, Reactors, and Control Research Group (CRC), Department of Chemical and Environ. \\ Engineering, University of Oviedo, Julián Clavería 8, 33006 Oviedo, SPAIN. \\ ${ }^{2}$ College of Engineering, Mathematics and Physical Sciences, University of Exeter, North Park Road \\ EX4 4QF, Exeter, UNITED KINGDOM \\ * Corresponding author. Phone: 34-985 103437. E-mail: sordonez@uniovi.es
}

\begin{abstract}
Unconventional methane resources are usually diluted in air, which prevents their use as feedstock in chemical or thermal processes. Some of them (e.g. coal mine ventilation air or diluted landfill biogas) are emitted directly to the atmosphere without harnessing, increasing the contribution of methane to global warming. Gas permeation membranes offer an alternative for the concentration of these methane resources, increasing considerably their harnessing possibilities. Microporous materials, such as carbon molecular sieve, zeolite or metal organic frameworks, have emerged as alternative to polymeric materials for the preparation of these membranes.

The present work is based on simulations of the separation of methane and nitrogen mixtures, using SAPO-34 and carbon molecular sieve membranes. Mass transfer has been modelled in two scales: the membrane material (modelled using the Maxwell-Stefan multicomponent surface diffusion model) and the membrane module (based on the plug flow model). A sensitivity analysis of the influence of the main operating variables on the membrane performance has revealed that the most important ones are transmembrane pressure difference, methane feed concentration and membrane loading. It has been found that SAPO-34 membranes are more suited to concentrate methane in lean mixtures, while the carbon membrane perform better with rich mixtures.

The membrane process has been scaled-up for a feed gas flow rate of $1000 \mathrm{~m}^{3} / \mathrm{h}$ n.t.p. with target methane recovery of $70 \%$ for two cases: lean (1\%) and rich (50\%) methane feed mixtures.
\end{abstract}

Keywords: gas permeation; microporous membranes; mass transfer modeling; methane harnessing; process scale-up 


\section{Introduction}

Unconventional methane resources, i.e. different from natural gas, include important renewable and non-renewable ones, such as, coal bed and coal mine ventilation air methane, emissions from the natural gas extraction and distribution systems, biogas produced in landfills and anaerobic digestion processes, etc. Some of these methane sources are usually emitted to the atmosphere without harnessing, because methane is diluted with other gases (typically nitrogen, oxygen and carbon dioxide). Given that methane is a powerful greenhouse gas, the second in importance after carbon dioxide, it contributes to the uncontrolled global warming [1]. The concentration of methane in these unconventional resources opens the door to a range of chemical and thermal upgrading techniques. Chemical upgrading may include the transformation into syngas (dry or wet reforming) or methanol (partial oxidation) [2,3]. Thermal upgrading can be accomplished, depending on the concentration, using gas turbines, reciprocating machines or regenerative oxidizers [4-6].

Different separation operations have been proposed to separate or concentrate methane, such as, cryogenic distillation, absorption, adsorption or membrane separation [7-13]. Gas permeation membranes are based on the different transport rates through a porous membrane of the compounds of a mixture. Membranes have been successfully proposed to separate methane/carbon dioxide mixtures $[14,15]$. On the contrary, the separation of methane/nitrogen mixture has been studied to a lower extent, particularly for the case of low methane concentration emissions.

Methane and nitrogen are molecules with similar properties and size (kinetic diameter of 0.38 and $0.36 \mathrm{~nm}$, respectively, for methane and nitrogen). For this reason, their separation is a challenging task. Polymeric membranes are used in many industrial applications; however, they display low permeability and limited selectivity for the case of methane/nitrogen mixtures [7, 16]. A review of the application and scale-up of polymeric membranes in the natural gas sector can be found in the literature $[17,18]$. In the last years, a new family of microporous inorganic membranes has been developed, which can be a promising alternative for the separation of methane/nitrogen mixtures. These membranes have narrow pores of similar size to the gas molecules, so the gas adsorbs on the pore surface and, then, diffuses to the permeate side. Hence, the transport mechanism is ruled by surface diffusion. According to this mechanism, materials with a high adsorption capacity towards one of the compounds are able of permeating this compound at a faster rate [19].

Microporous membranes include carbon molecular sieve, zeolite and metal organic framework membranes. Carbon molecular sieve (CMS) membranes are obtained by high-temperature pyrolysis of some polymeric materials, such as, polyimide [20], ZIF-108 doped polyimide [21], poly(benzimidazole) [22] and polyvinylidene chloride-acrylate ter-polymer latex [23]. They contain 
micropores $(0.7-2 \mathrm{~nm})$ and ultramicropores $(<0.7 \mathrm{~nm})$, the latter ones being responsible of the high separation selectivity for methane/nitrogen mixtures, e.g. permselectivity of 6 [20] and 8 [22] have been reported.

Zeolite membranes have a three-dimensional crystalline structure with uniform pore size distribution. SSZ-13 and SAPO-34 (both with pore size of $0.38 \mathrm{~nm}$ ) have been proposed as membranes for the separation of methane $[7,24]$. Compared to the SSZ-13 membranes, SAPO-34 membranes are more attractive, because of their high nitrogen permeance [24]. SAPO-34 membranes have already been prepared in cylindrical shape, offering a selectivity in the range 5-8 for methane/nitrogen mixtures [25-28]. As for SSZ-13 membrane, selectivity as high as 12 has been reported [25]. Decadodesil 3R (DD3R, pore size $0.36 \times 0.44 \mathrm{~nm}$ ) membranes are promising with good separation performance (methane/nitrogen selectivity in the range 20-45) [29].

Metal organic framework (MOF) membranes, similarly to zeolite membranes, present a highly regular pore structure. This family of materials is very promising, because there is a great range of organic blocks and metal cations to choose from, making pore geometry and properties highly tuneable. Inside this category, zeolite imidazole frameworks (ZIF) stand out due to their adsorption capabilities [30, 31]. Membranes made of ZIF-8 have been prepared and studied for gas permeation $[32,33]$. However, most previous studies are focused on the separation of hydrogen and carbon dioxide/nitrogen mixtures. Further research is needed for the case of methane/nitrogen mixtures. Given the recent advances in the membrane separation regarding methane/nitrogen mixtures, two membranes have been considered for the study of the present work: SAPO-34 and carbon molecular sieve membranes. These two membranes are representative of their respective microporous material groups.

The present work is based on the use of model simulations at two scales: permeation inside the membrane material and mass transfer in the membrane module. Using this approach, it is possible to predict permeation rates, but also determine the concentration profiles inside the membrane modules. However, most modelling works are only focused on the simulation of the permeation inside the membrane material. The present work provides new insights into the further application of the membranes for the separation of methane/nitrogen mixtures. Hence, the simulation of the membrane module is considered critical to obtain information regarding the process assessment and scale-up. For this purpose, first, a sensitivity analysis of the main operating variables of the process has been carried out to determine the impact of these variables and optimize their values. Then, the design and scale-up of the membrane process has been done for two cases: rich and lean methane sources. 


\section{Materials and methods}

\subsection{Modelling of membrane permeation}

In micropore membranes, the pore size and molecule diameter are similar, so molecules never scape completely from the surface force field. Consequently, surface forces become the dominant mass transport phenomena. The Maxwell-Stefan model can be extended to describe the multicomponent surface diffusion in micropores [19, 34]:

$$
-\frac{\theta_{i}}{R T} \nabla \mu_{i}=\sum_{\substack{j=1 \\ j \neq i}}^{n} \frac{\theta_{j} N_{i}^{S}-\theta_{i} N_{j}^{S}}{\rho_{S} q_{s} \theta_{i j}^{S}}+\frac{N_{i}^{S}}{\rho_{S} q_{S} \theta_{i}^{S}}
$$

Where $\rho_{S}$ is the density of the solid, $q_{s}$ is the concentration of adsorbed species at saturation, $N_{i}^{S}$ are the surface diffusion fluxes, $\theta_{i}$ is the fractional surface coverage $\left(\theta_{i}=q_{i} / q_{s}\right)$ and $\theta^{S}$ are the surface Maxwell-Stefan diffusivities.

Assuming local equilibrium between surface and adjacent fluid, the surface chemical potential $\left(\mu_{i}\right)$ can be expressed as follows:

$$
\frac{\theta_{i}}{R T} \nabla \mu_{i}=\sum_{j=1}^{n} \Gamma_{i j} \nabla \theta_{j}, \quad \Gamma_{i j}=\theta_{i} \frac{\partial \ln p_{i}}{\partial \theta_{i}}
$$

Where $\Gamma_{i j}$ are the Maxwell-Stefan thermodynamic factors, obtained using an adsorption isotherm expression, and $p_{i}$ are the partial pressures (at high pressure, fugacity should be used instead of partial pressures to account for non-ideal gas behaviour). For the case of the Langmuir adsorption isotherm, the Maxwell-Stefan thermodynamic factors for a binary mixture are [19]:

$$
\Gamma_{i i}=1+\frac{\theta_{i}}{1-\left(\theta_{1}+\theta_{2}\right)}, \quad \Gamma_{i j}=\frac{\theta_{i}}{1-\left(\theta_{1}+\theta_{2}\right)}
$$

The combination of equations (1) and (2) gives the final Maxwell-Stefan model. Flux expression in $n$ dimensional matrix is [35]:

$$
\left(N_{i}^{S}\right)=-\rho_{S}\left[B^{S}\right]^{-1}[\Gamma]\left(\nabla q_{i}\right)
$$

Where the elements of $\left[B^{S}\right]$ are defined as:

$$
B_{i i}^{S}=\frac{1}{\theta_{i}^{S}}+\sum_{\substack{j=1 \\ j \neq i}}^{n} \frac{\theta_{j}}{\theta_{i j}^{S}}, \quad B_{i j}^{S}=-\frac{\theta_{i}}{\theta_{i j}^{S}}
$$

The interacting surface Maxwell-Stefan diffusivities, $\theta_{i j}^{S}$, represents the coupling effects, i.e. the interactions between molecules. These parameters can be obtained experimentally or estimated 
using single-compound surface Maxwell-Stefan diffusivities, $\theta_{i}^{S}$. A detailed study about coupling effects can be found elsewhere [36]. For the case of microporous materials formed by large cavities separated by narrow pores, such as, SAPO-34, ZIF-8 and other zeolite and MOF structures, the pore aperture is so small that only one molecule can diffuse at the same time. In these situations, the coupling effects can be made negligible at pressures below 10 bar, i.e. $1 / \theta_{i j}^{S} \approx 0[36]$.

Equation (4) provides the molar flux as a function of the concentration gradient of adsorbed species $\left(q_{i}\right)$. In order to calculate the molar flux, this equation must be combined with the mass balance to the membrane thickness, eq. (6), and solved using as boundary conditions the concentration of adsorbed species at both membrane sides. For 1D rectangular coordinates, this is traduced into the following set of equations, where $z$ is the membrane thickness coordinate.

$$
\begin{array}{ll}
\frac{d N_{i}^{S}}{d z}=0, & \left.q_{i}\right|_{z=0}=q_{i, \text { retentate }} \\
\frac{d q_{i}}{d z}=-\frac{1}{\rho_{S}}\left[B^{S}\right][\Gamma]^{-1}\left(N_{i}^{S}\right), & \left.q_{i}\right|_{z=\delta}=q_{i, \text { permeate }}
\end{array}
$$

The concentration of adsorbed species at both membrane sides, $q_{i \text {,retentate }}$ and $q_{i \text {,permeate, }}$ are calculated using the adsorption isotherm, evaluated at the corresponding partial pressures at both membrane sides.

Note that $\left[B^{S}\right]$ and $[\Gamma]$ of equations (6) and (7) depend on the concentration of adsorbed species $\left(q_{i}=q_{s} \theta_{i}\right)$. Hence, these differential equations correspond to a boundary value problem, which have been solved using a code written in MATLAB based on bvp $4 \mathrm{C}$ function.

The membrane permeation model requires two sets of parameters: a multicomponent adsorption isotherm (equilibrium) and Maxwell-Stefan surface diffusivities (kinetics). In the Supplementary Information, it is detailed how these parameters are determined from literature experimental data.

\subsection{Modelling of the membrane module}

Membranes are installed inside modules, so once the membrane permeation is modelled by adequate equations, as explained in the previous section, the modelling should be extended to the module. The module is responsible for introducing and distributing the feed on one side of the membrane and collecting the permeate on the other side. The type of flow pattern inside the membrane module may limit the degree of separation of a given membrane. For this reason, the membrane module should be modelled, if the purpose of the model is the design, scale-up or optimization of the membrane separation. 
In the present work, hollow fibre membrane modules have been chosen to support the membrane materials. These modules are made of an array of several fibres of small diameter, stack together inside a cylindrical shell. The feed is typically introduced through the inside of the fibres, while the permeate stream is collected from the shell side. In both compartments, fibre and shell sides, the flow pattern is approximated by the ideal plug flow. The plug flow model offers two possible flow configurations for the feed and permeate streams: co-current and counter-current. In co-current configuration, retentate and permeate outlets are on the same side of the membrane, so the gas flow direction is the same for the fibre and shell sides. On the contrary, in counter-current configuration, the gas flows are in opposite directions.

The model equations are obtained from separate mass balances in 1D to the retentate $(R)$ and permeate $(\mathrm{P})$ sides of the module. All the fibres are considered to exhibit the same behaviour, so they are modelled as a whole. The module is considered isothermal.

$$
\begin{aligned}
& \frac{d F_{R i}}{d x}=-J_{i} A_{m},\left.\quad F_{R i}\right|_{x=0}=F_{0} y_{i, 0} \quad \text { (retentate) } \\
& \frac{d F_{P i}}{d x}=J_{i} A_{m},\left.\quad F_{P i}\right|_{x=0}=F_{\mathrm{Sw}} y_{i, \mathrm{sw}} \quad \text { (permeate, co current flow) } \\
& \frac{d F_{P i}}{d x}=-J_{i} A_{m},\left.\quad F_{P i}\right|_{x=1}=F_{\mathrm{sw}} y_{i, \mathrm{sw}} \quad \text { (permeate, counter current flow) }
\end{aligned}
$$

Where $x$ is the dimensionless axial coordinate of the module, $F_{i}$ is the molar flow rate of compound $i, y_{i}$ is the molar fraction of compound $i, A_{m}$ is the membrane area and $J_{i}$ molar flux permeated through the membrane. Sometimes, a sweep gas is introduced in the permeate side of the membrane to decrease the concentration of the permeated compounds and increase the partial pressure difference. This is accounted for by the corresponding boundary conditions, as shown in the previous equations (denoted as sw). However, in the present work, no sweep gas is used, because this leads to a decrease in methane concentration (i.e. $F_{\mathrm{sw}}=0$ ).

This type of 1D model has been validated experimentally for commercial polymeric membrane modules by different authors $[14,37,38]$. Permeation data of different gas mixtures $\left(\mathrm{CH}_{4} / \mathrm{CO}_{2}, \mathrm{~N}_{2} / \mathrm{O}_{2}\right.$, etc.) has been predicted with good results. Haddadi et al. [38] evaluated the performance of 1D and 3D models for membrane modules. They found that 1D models are suitable for efficient process scale-up and optimization (e.g. selection of flow configuration, transmembrane pressure difference or feed flow rate adjustment), while 3D models can be used for a detailed analysis of the module (investigation of geometrical effects like spacers or flow effects like concentration polarization). The present work is focused on the process assessment and scale-up and, hence, a 1D model has been selected. 
The differential equations describing the behaviour of the membrane module have been solved using a code written in Matlab based on function ode15s (for co-current flow) or bvp $4 \mathrm{c}$ (for countercurrent flow). The permeation flux $\left(U_{i}\right)$ varies along the membrane length, due to changes in the compound concentrations. This means that the set of eq. (6) and (7) are nested inside eq. (8) to (10). Thus, for a given set of the axial coordinate in the membrane module $x$, with known retentate and permeate concentrations, the permeated flux is calculated from eq. (6) and (7), i.e. $J_{i}=\left.N^{s}\right|_{z=\delta}$. Then, this permeated flux is used in eq. (8) to (10) to solve the molar flow rates and another set of retentate and permeate concentrations are obtained.

\section{Results and discussion}

\subsection{Membrane performance}

In this section, the performance of the membranes has been analysed and compared to each other. The performance has been measured in terms of permeance $\left(\Pi_{\mathrm{i}}\right)$, which is defined as follows:

$$
J_{i}=\Pi_{\mathrm{i}} \Delta p_{i}
$$

Where $J_{i}$ is the permeated flux and $\Delta p_{i}$ is the partial pressure difference between the retentate and permeate sides. The membrane permeance is related to the permeability $\left(\mathcal{P}_{i}\right)$ using $\mathcal{P}_{i}=\Pi_{\mathrm{i}} \delta$, where $\delta$ is the thickness of the membrane active layer (for $\delta$ in $\mu \mathrm{m}$ and $\Pi_{\mathrm{i}}$ in GPU, $\mathcal{P}_{i}$ is obtained in barrer). The permeated flux, $J_{i}=\left.N^{s}\right|_{z=\delta}$, has been simulated using the multicomponent surface diffusion model, eq. (4) to (7), and the permeance calculated using eq. (11).

Figure 1 shows the experimental and predicted permeances at $293 \mathrm{~K}$ for the SAPO-34 ( $\Delta p=138 \mathrm{kPa})$ and carbon $(\Delta p=85 \mathrm{kPa})$ membranes. More information about the structure and properties of these membranes can be found in the Supplementary Information.

For the SAPO-34 membrane, nitrogen single-gas permeance is 435 GPU ( 2700 barrer), which is 8.7

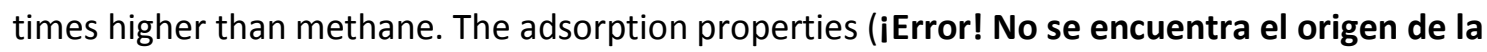
referencia.) actually exhibit the opposite behaviour with $K=q_{s} b$ being 3.1 times higher for methane. On the contrary, nitrogen surface diffusivity $\theta_{S}$ is 23 times higher than methane, which is attributed to the different molecule sizes. This explains the differences observed in the permeances. Figure 1 also includes the mixture permeances predicted by the model with nitrogen mixture permeance decreasing a bit on increasing methane mole fraction in the gas phase. This can be due to higher methane adsorbed concentrations that may negatively affect to the nitrogen permeation. On the contrary, methane permeance is almost independent of concentration. 


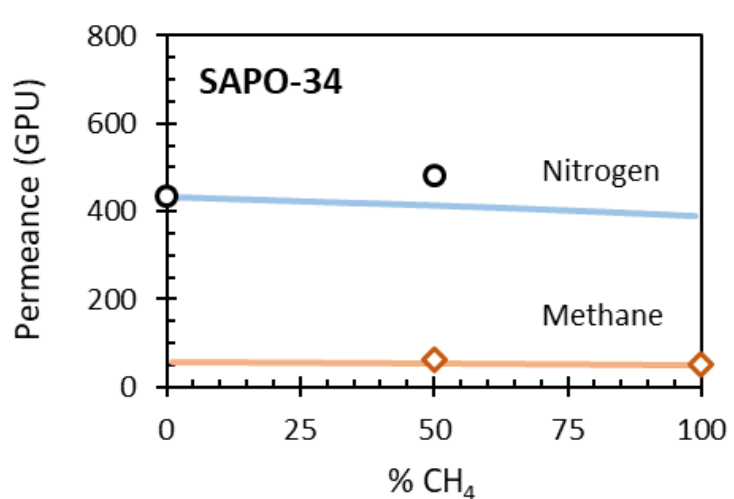

a)

Figure 1. Membrane permeance at $293 \mathrm{~K}$ (symbols: experimental data; lines: model predictions):

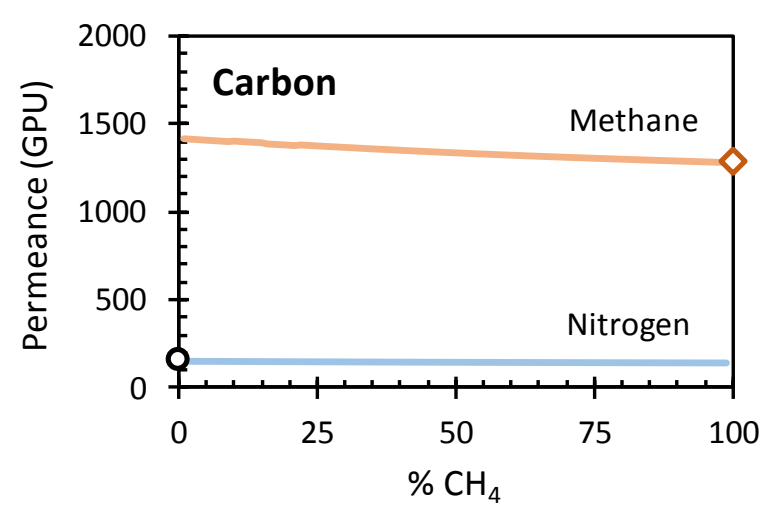

b)

a) SAPO-34 ( $\Delta p=138 \mathrm{kPa}$ ) [24] and b) carbon ( $\Delta p=85 \mathrm{kPa}$ ) [23] membranes.

The fact that nitrogen permeance is higher than that of methane for SAPO-34 membranes means that nitrogen tends to concentrate in the permeate side and methane in the retentate side. The $\mathrm{N}_{2} / \mathrm{CH}_{4}$ separation factor varies with methane concentration, as shown in Figure 2, from 5.2 at low concentration values to 2.2 at the high ones. The separation factor is defined as the ratio of permeate and retentate mole fractions of one compound divided by that of the other one. These results suggest that SAPO-34 membrane is a good membrane candidate for feeds diluted in methane, the separation factor being higher at these conditions.

Carbon membrane stands out by a very high methane single-gas permeance, 1280 GPU (3200 barrer), which is 8.4 times higher than that of nitrogen. This is just the opposite behaviour to SAPO34 membrane. The adsorption capacity of methane in the carbon membrane is higher than nitrogen, with $K=q_{s} b$ being 3.1 times higher. In addition, methane surface diffusivity $\theta_{s}$ is 3 times faster than that of nitrogen, which is explained by stronger interactions between methane molecules and the carbon surface.

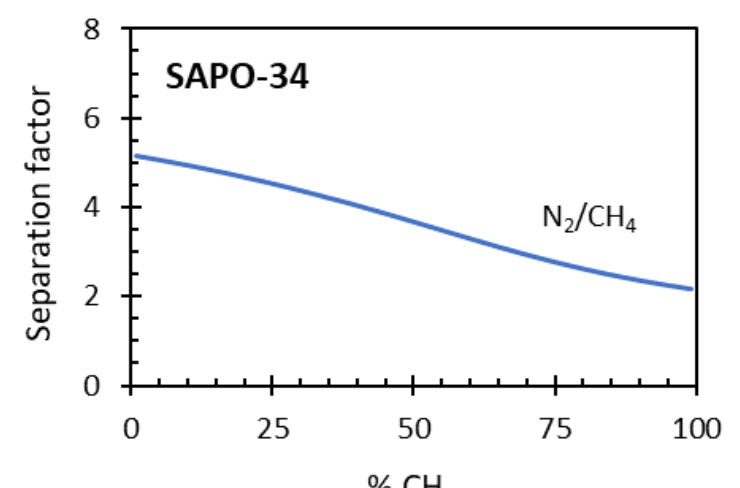

a)

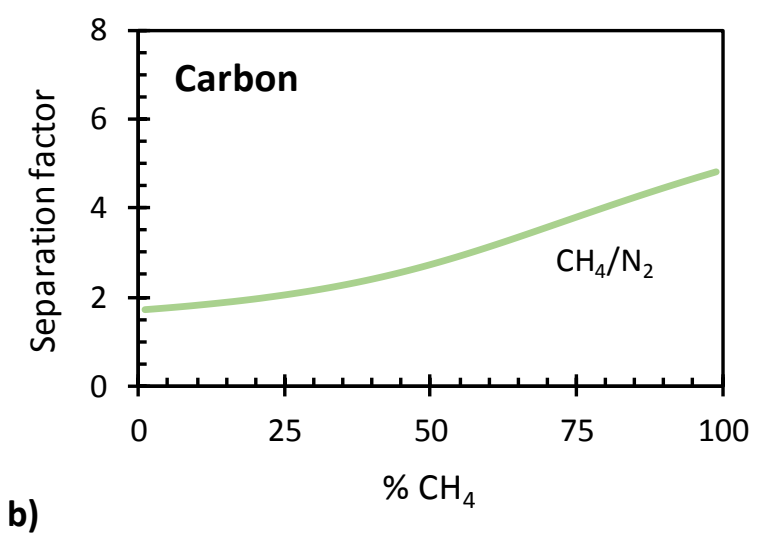

Figure 2. Membrane separation factor at $293 \mathrm{~K}$ (model predictions): a) SAPO-34 ( $\Delta p=138 \mathrm{kPa}$ ) and b) carbon $(\Delta p=85 \mathrm{kPa})$ membranes. 
Differently from the SAPO-34 membrane, in the carbon membrane, methane concentrates in the permeate side and nitrogen in the retentate side. Hence, both membranes should be compared in term of the gas which permeates at a faster rate, either methane or nitrogen. Moreover, given that the active layer of both membranes is different $(6.2 \mu \mathrm{m}$ and $2.5 \mu \mathrm{m}$, respectively, for the SAPO-34 and carbon membranes), it is better to compare the membrane permeability of both materials. According to this, nitrogen permeability is 2700 barrer in SAPO-34 and methane permeability is 3200 barrer in the carbon membrane. These figures are quite similar, being methane permeability in the carbon membrane only $20 \%$ higher.

The separation factor has a similar range to SAPO-34 membrane, but with the opposite behaviour with respect to methane concentration. It is low (1.7) at low methane concentrations and increases (up to 4.8) at high concentrations. As a result, this membrane is more suited for feeds rich in methane that needs removal of some minor quantities of nitrogen.

\subsection{Simulation of the membrane module}

The considered membrane modules are not commercially available. For this reason, in order to gain insight into the applications of the operation, the performance of the membrane module has been studied by means of simulations. In the present work, a hollow fibre membrane module has been considered. This module has been modelled according to the plug flow model, as explained in section 2.2. The plug flow model is simple, but it can determine the concentration profiles along the membrane length accurately. Hence, this model can extrapolate the performance of the membrane to the whole module, with gas concentrations changing from one point to the other, due to mass transfer.

Figure 3 and 4 compare the results of the simulations for both membranes, SAPO- 34 and carbon. The conditions correspond to a methane feed concentration of $10 \%$, transmembrane pressure difference of 4 bar, co-current flow configuration and membrane loading, $F_{0} / A_{m}=0.0530 \mathrm{~mol} / \mathrm{m}^{2} \mathrm{~s}$ for SAPO-34 and $F_{0} / A_{m}=0.0595 \mathrm{~mol} / \mathrm{m}^{2} \mathrm{~s}$ for carbon. The membrane loading, $F_{0} / A_{m}$, is defined as the ratio of molar feed flow rate $\left(F_{0}\right)$ to membrane area $\left(A_{m}\right)$. The membrane loading $F_{0} / A_{m}$ is quite useful for membrane sizing, because membranes with the same $F_{0} / A_{m}$ exhibit the same performance, regardless of the membrane size. In this case, the membrane loading that determines a methane recovery of $70 \%$, in each membrane, has been selected. For this reason, the membrane loadings are a bit different for both membranes. In our opinion, it is better to compare membranes for the same methane recovery, instead of, for example, membrane area. 


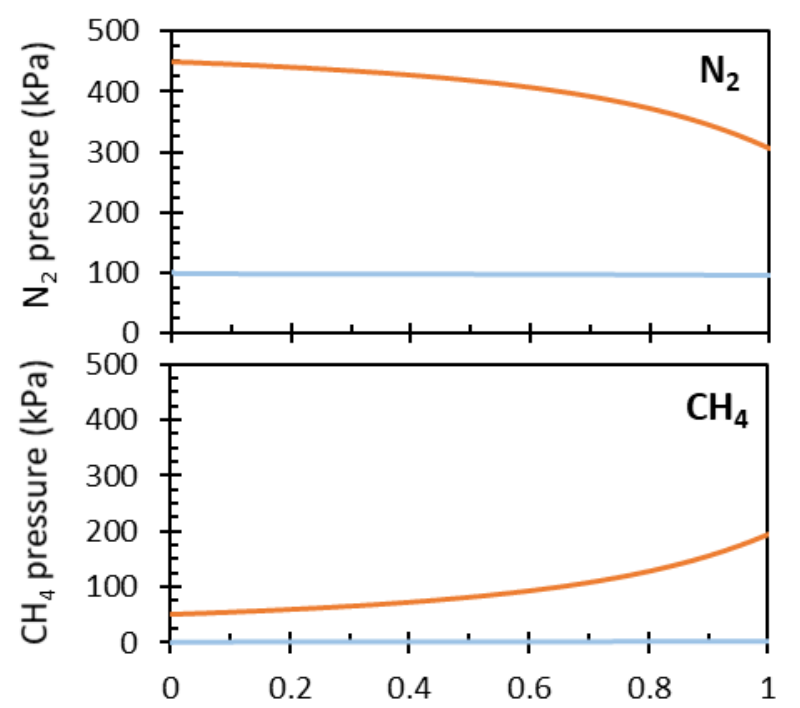

a)

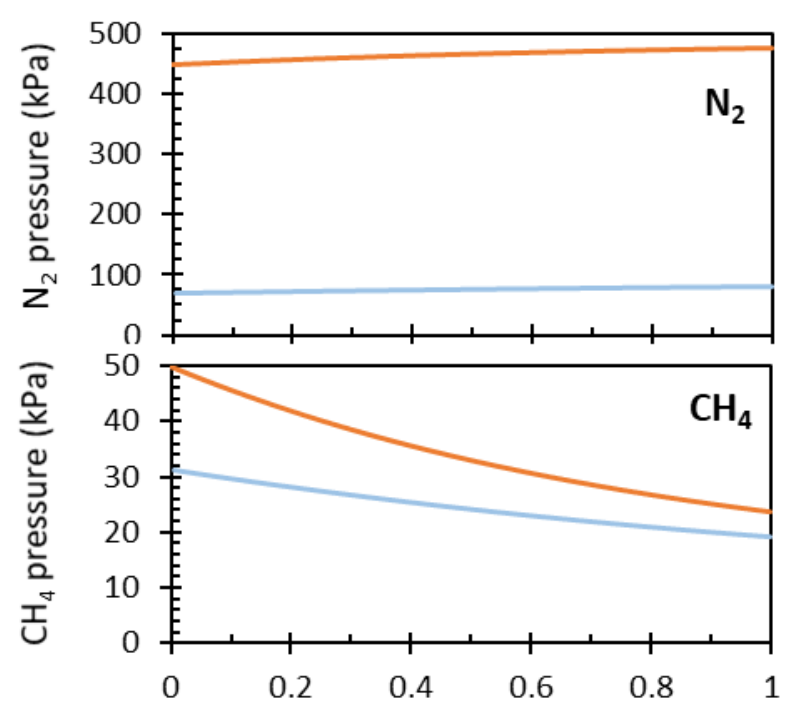

b)

Dimensionless length $(x)$

Figure 3. Simulation of the membrane module: partial pressure profiles along the membrane length for the retentate (-) and permeate (-) sides. Conditions: $10 \% \mathrm{CH}_{4}$ feed, $\Delta \mathrm{p}=4 \mathrm{bar}$, co-current flow and $70 \%$ methane recovery. a) SAPO-34 $\left(F_{0} / A_{m}=0.0530 \mathrm{~mol} / \mathrm{m}^{2} \mathrm{~s}\right)$. b) carbon $\left(F_{0} / A_{m}=0.0595 \mathrm{~mol} / \mathrm{m}^{2} \mathrm{~s}\right)$.

The partial pressure profiles, which are the driven force for mass transfer, are depicted in Figure 3. For the SAPO-34 membrane (Figure 3a), nitrogen partial pressure of the retentate side decreases progressively along the membrane length. Thus, as shown in Figure 4a, nitrogen permeated flux is much higher than that of methane, due to two factors: a higher partial pressure difference and a higher permeance (see eq. (14)). Note that, in SAPO-34 membrane, nitrogen permeance is higher than that of methane (see Figure 1a). As a consequence of this, methane partial pressure in the retentate side increases from $50 \mathrm{kPa}(10 \%)$ to $196 \mathrm{kPa}(39 \%)$; this corresponds to an increase of 3.9 times the feed mole fraction. The permeate side is essentially nitrogen, with partial pressure being almost constant along the membrane length.

The carbon membrane exhibits essentially the opposite behaviour to the SAPO-34 one. In the retentate side, partial pressure profile along the membrane length decreases for methane and increases a bit for nitrogen (Figure $3 b$ ). As explained before, in the carbon membrane, methane concentrates in the permeate side. However, the permeated flux is higher for nitrogen (Figure 4b), as for the SAPO-34 membrane. This behaviour can be explained in terms of eq. (14). In the carbon membrane, methane permeance is higher (see Figure $1 b$ ). On the contrary, the partial pressure difference is lower for methane (for example, in the middle point of the membrane, $x=0.5$, it is $9 \mathrm{kPa}$ for methane and $391 \mathrm{kPa}$ for nitrogen). This explains the higher permeated flux for nitrogen. Despite this the difference between the permeated flux of methane and nitrogen is small enough to make it 
possible for the concentration of methane in the permeate side. According to the results of Figure $3 \mathrm{~b}$, the permeate outlet stream contains $19 \mathrm{kPa}$ of methane (19\%), which means a concentration factor of 1.9 times of the feed mole fraction.

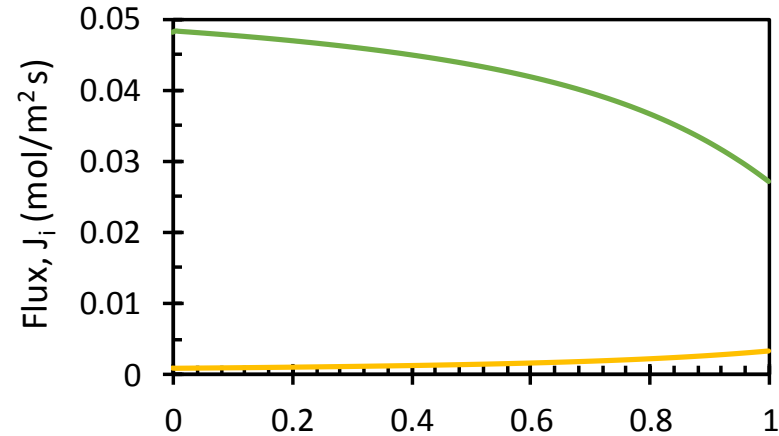

a)

Dimensionless length $(x)$

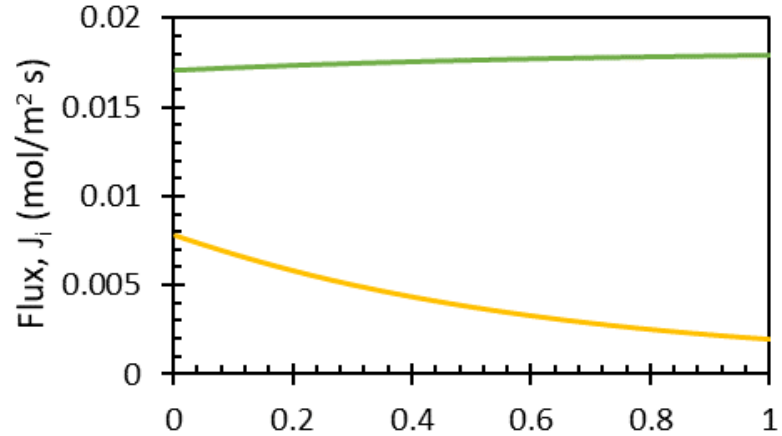

b)

Dimensionless length $(x)$

Figure 4. Simulation of the membrane module: permeated flux profiles along the membrane length for methane (-) and nitrogen (-). Conditions: $10 \% \mathrm{CH}_{4}$ feed, co-current flow, $\Delta \mathrm{p}=4$ bar and $70 \%$ methane recovery. a) SAPO-34 $\left(F_{0} / A_{m}=0.0530 \mathrm{~mol} / \mathrm{m}^{2} \mathrm{~s}\right)$. b) Carbon $\left(F_{0} / A_{m}=0.0595 \mathrm{~mol} / \mathrm{m}^{2} \mathrm{~s}\right)$.

\subsection{Sensitivity analysis}

The aim of the sensitivity analysis is the evaluation of the main design and operational parameters on the behaviour of the membrane. Thus, the membrane performance has been measured in terms of methane recovery (i.e. the fraction of the methane from the feed that is separated) and concentration factor (i.e. ratio of methane mole fractions in the product and feed streams). The influence of the following variables has been studied: methane feed concentration, flow configuration in the membrane module (co-current or counter-current), transmembrane pressure difference $(\Delta p)$ and membrane loading $\left(\mathrm{F}_{0} / \mathrm{A}_{m}\right)$.

The sensitivity analysis has been done for the SAPO-34 and carbon membranes, using the model described in the Material and Methods section.

\subsubsection{Influence of transmembrane pressure difference}

In the first place, the influence of transmembrane pressure difference has been analysed for cocurrent or counter-current flow configurations. The results are presented in Figure 5 (SAPO-34) and Figure 6 (carbon) for $1 \%$ methane feed concentration. 
In SAPO-34 membranes, methane concentrates in the retentate side, as discussed in section 3.2. For this reason, an increase in the membrane loading $\left(F_{0} / A_{m}\right)$ results in a decrease in the permeated flux and, hence, an increase in methane recovery (Figure 5a). However, the concentration factor decreases (Figure 5b), which means that the methane separated in the retentate will be less concentrated. It should be noted that the curves of Figure 5 are very sharp, particularly for $\Delta p=4$ bar, with concentration factor decreasing from 10 to 3 when recovery only increases from $60 \%$ to $80 \%$. For this reason, an adequate selection of the design membrane loading $F_{0} / A_{m}$ is critical.

The transmembrane pressure difference is a parameter with a strong influence on the membrane performance. Thus, on increasing pressure difference the curves of Figure 5 are shifted toward higher membrane loadings, which means that lower membrane area would be required (for the same feed flow rate). The impact on the concentration factor is also positive with higher methane concentrations being possible for the same recovery. For example, for 70\% recovery (co-current), concentration factor increases from 3.1 at $\Delta p=1$ bar to 6.3 at $\Delta p=4$ bar.
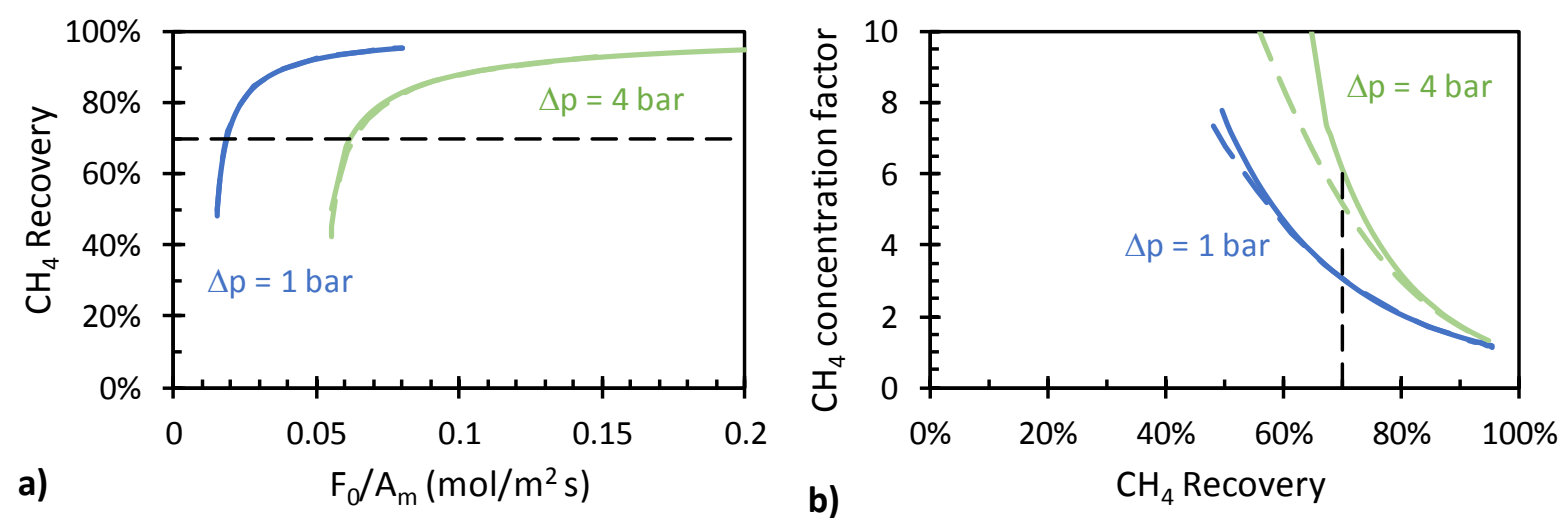

a)

$$
\mathrm{F}_{0} / \mathrm{A}_{\mathrm{m}}\left(\mathrm{mol} / \mathrm{m}^{2} \mathrm{~s}\right)
$$

Figure 5. Influence of transmembrane pressure difference and flow configuration on the performance of the SAPO-34 membrane. Conditions: $1 \% \mathrm{CH}_{4}, \Delta \mathrm{p}=1$ bar (-) and $\Delta p=4$ bar (-). Flow configuration: co-current (solid lines) counter-current (dashed lines).

The carbon membrane exhibits a different behaviour, because methane is concentrated in the permeate side of the membrane. Methane recovery decreases on increasing the membrane loading $\mathrm{F}_{0} / \mathrm{A}_{\mathrm{m}}$ (Figure 6), but this decrease is not as sharp as for the case of SAPO-34 membrane (particularly for $\Delta p=4$ bar). Thus, at low $F_{0} / A_{m}$ values, the permeate flow rate is high, which leads to a higher methane recovery, but with lower concentration factor (low methane concentration). 


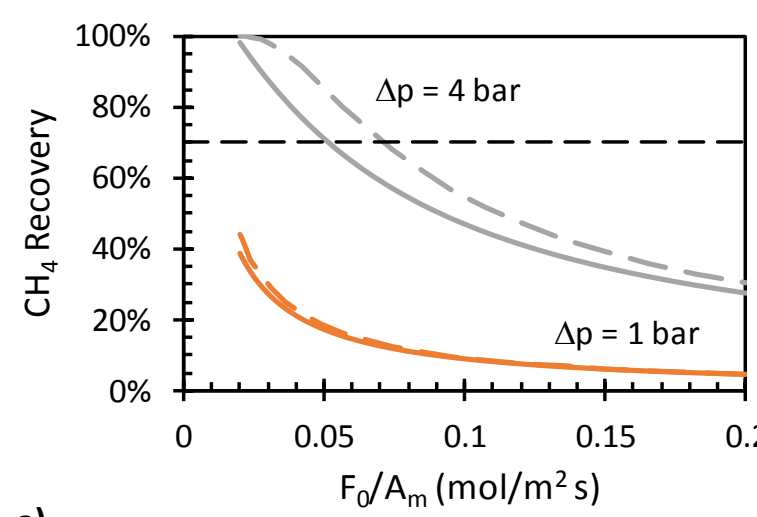

a)

$$
\mathrm{F}_{0} / \mathrm{A}_{\mathrm{m}}\left(\mathrm{mol} / \mathrm{m}^{2} \mathrm{~s}\right)
$$

Figure 6. Influence of transmembrane pressure difference and flow configuration on the performance of the carbon membrane. Conditions: $1 \% \mathrm{CH}_{4}, \Delta \mathrm{p}=1$ bar (-) and $\Delta \mathrm{p}=4$ bar (-). Flow configuration: co-current (solid lines) counter-current (dashed lines).

Transmembrane pressure difference is of key importance for this membrane. Thus, in the permeate side, methane concentration increases, which may lead to a decrease in the transmembrane partial pressure difference. This decrease must be overcome with an increase in the transmembrane pressure difference. Otherwise, the permeated flux will fall to zero, due to the absence of mass transfer driving force. This can be observed in Figure 6. For $\Delta p=1$ bar, methane recovery and concentration factor are very low, because the partial pressure gradient is low. Consequently, higher transmembrane pressure differences are recommended for this membrane.

\subsubsection{Influence of the flow configuration}

The flow configuration, co-current or counter-current, has little influence on the performance of the SAPO-34 membrane. It has been observed a concentration factor a bit higher for co-current flow (Figure $5 b$ ). This is due to the type of membrane with methane concentrating in the retentate side. For the carbon membrane, the influence of the flow configuration is analysed at $\Delta p=4$ bar. For the same membrane loading $F_{0} / A_{m}$, both methane recovery and concentration factor are higher at counter-current flow (Figure 6). Considering the same methane recovery of $70 \%$, the concentration factor is 1.9 for co-current and 2.6 for counter-current flow. This means that more methane and at a higher concentration can be separated using counter-current flow. For the carbon membrane, for which methane concentrates in the permeate side, counter-current flow configuration is better than co-current one. 


\subsubsection{Influence of methane feed concentration}

The influence of methane feed concentration has been studied for a transmembrane pressure difference of 4 bar. Methane recovery and concentration factor of SAPO-34 membrane are depicted in Figure 7 for co-current and counter-current flow configuration. On increasing methane feed concentration, recovery curves maintain a similar shape, but shifted towards lower membrane loadings $F_{0} / A_{m}$ (Figure $7 a$ and $c$ ). This means that the area required by the membrane to achieve the same methane recovery increases. Methane feed concentration has a marked influence on the concentration factor (Figure $7 b$ and $d$ ). The shape of the curve changes completely and, hence, the influence of methane recovery on the concentration factor. At low concentrations (1\%), this influence is very strong with a sharp decrease in the concentration factor on increasing recovery. On the contrary, at high concentrations $(50 \%)$, the curve is very flat.

The flow configuration has no influence on methane recovery, even for high methane feed concentrations, and the concentration factor is slightly higher for co-current flow configuration. Hence, this flow configuration is the one recommended for this type of membrane with methane concentrating in the retentate side.
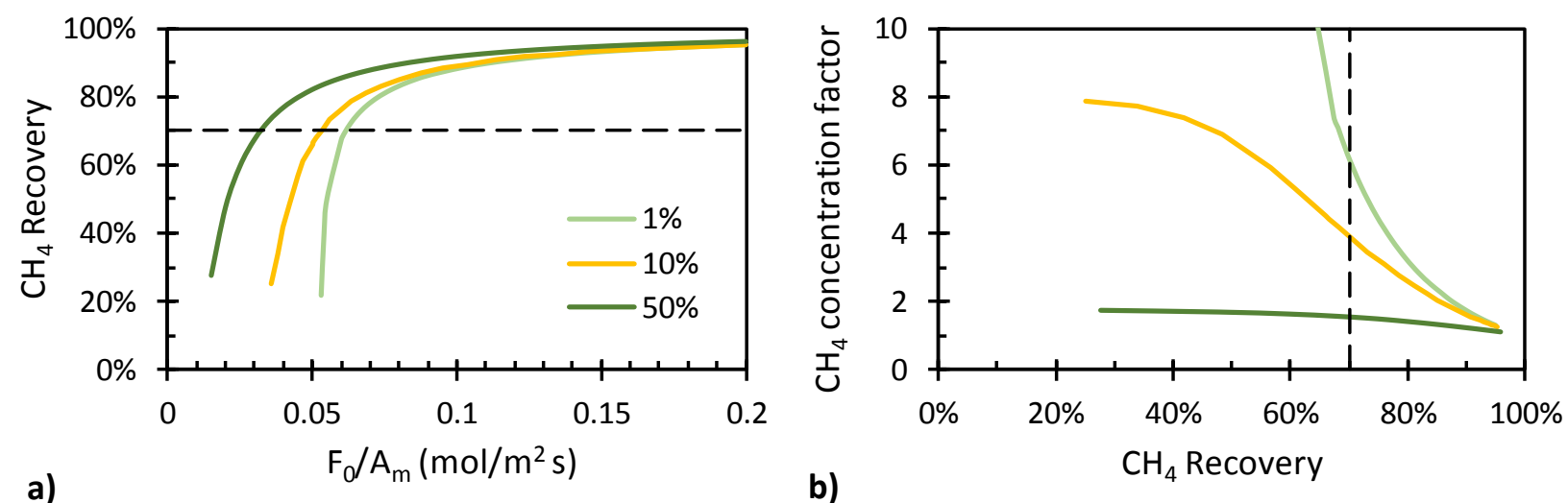

a)

b)
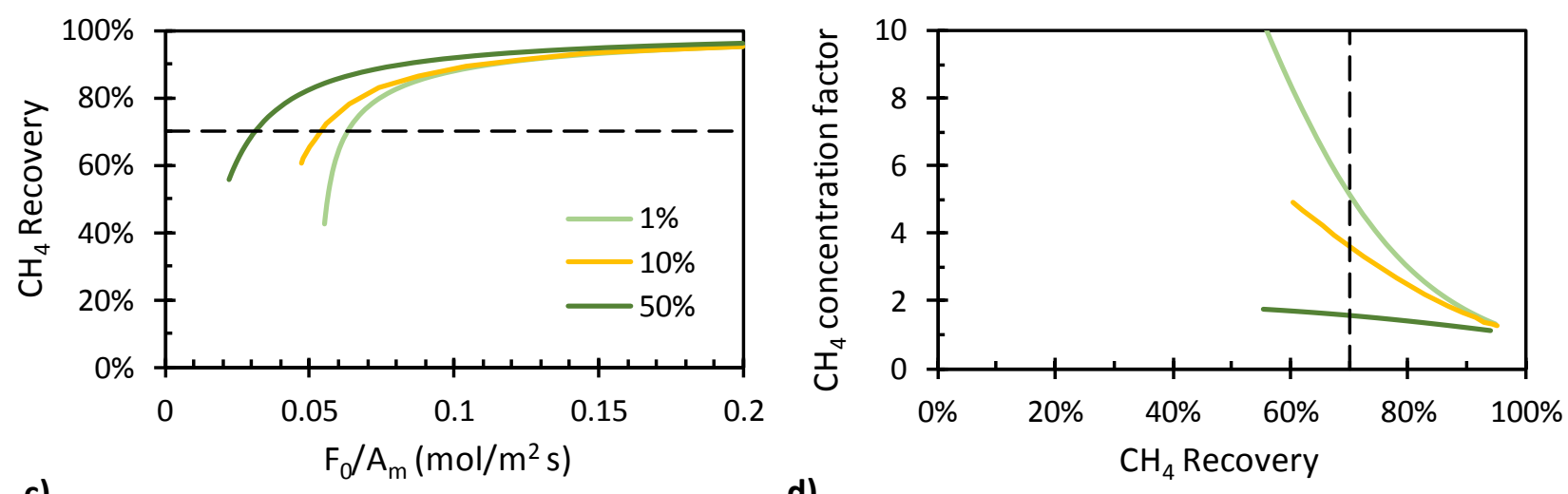

d)

Figure 7. Influence of methane feed concentration on the performance of the SAPO-34 membrane:

(-) $1 \%,(-) 10 \%$ and (-) $50 \% \mathrm{CH}_{4} . \Delta p=4$ bar. Flow configuration: co-current (a and b) countercurrent ( $c$ and d), 
The carbon membrane has been analysed in Figure 8. As shown, this membrane has the opposite behaviour to the SAPO-34 one: on increasing methane feed concentration, the curves of methane recovery shift to higher membrane loadings $F_{0} / A_{m}$. Hence, a lower membrane area is needed for higher methane feed concentrations to obtain the same recovery value. In this membrane, methane permeance is higher than nitrogen one, which means that methane concentrates in the permeate side. When methane feed concentration is higher, the transmembrane partial pressure difference is also higher, which results in a higher permeation flux and, hence, a lower membrane area is required to process the same feed flow rate. Similar to the SAPO-34 membrane, the concentration factor decreases with increasing methane feed concentration (Figure $8 \mathrm{~b}$ and d). However, this decrease is not as marked as for SAPO-34 membrane and the shape of the curve remains very similar for all the concentration values.

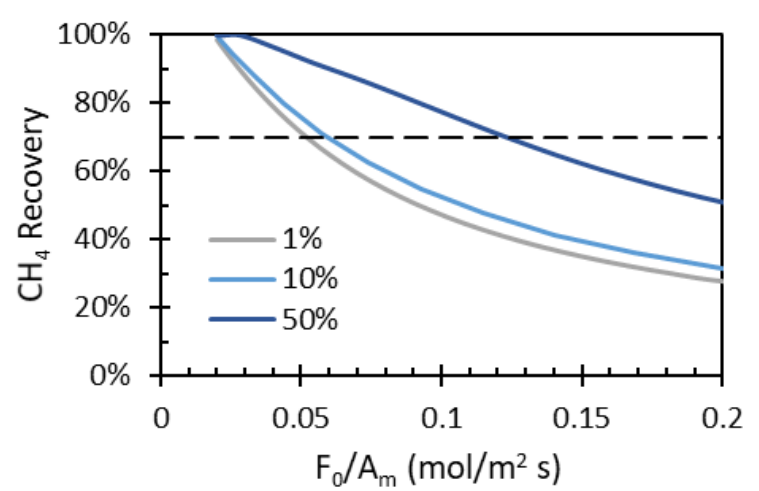

a)

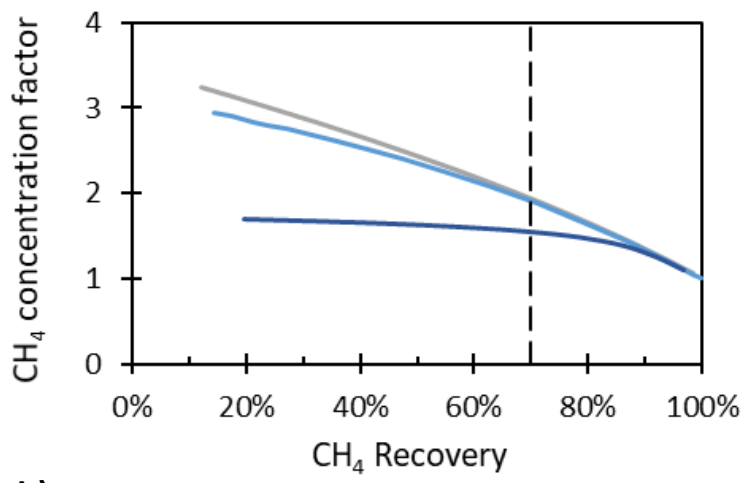

b)
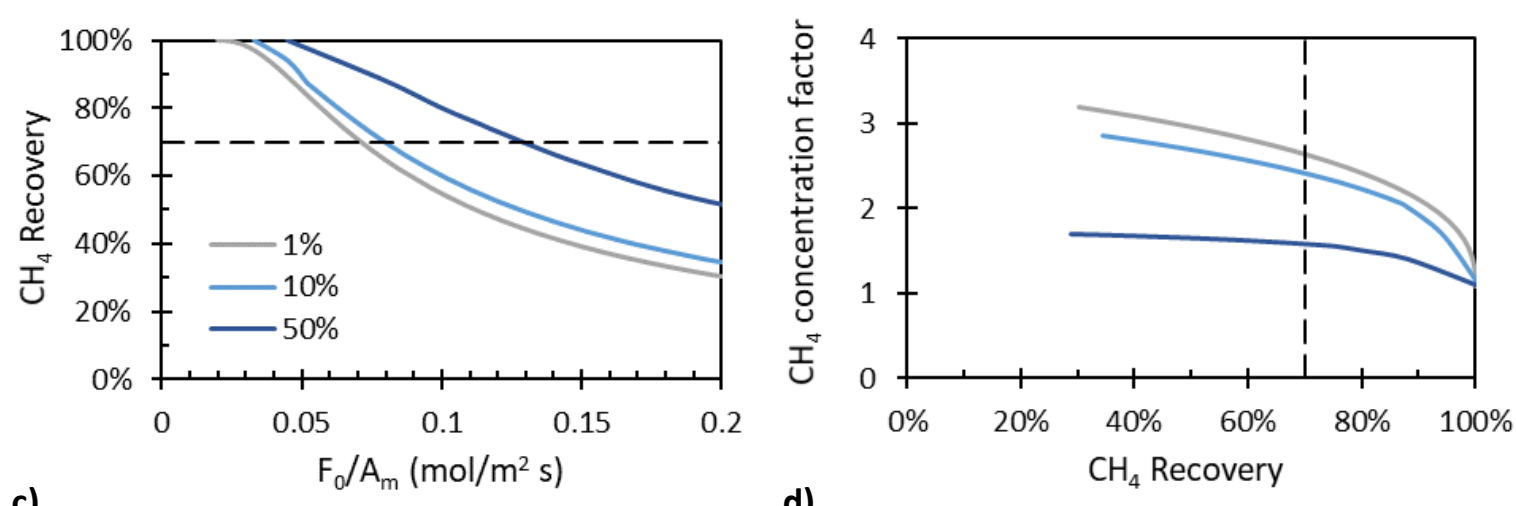

Figure 8. Influence of methane feed concentration on the performance of the carbon membrane: (-) $1 \%,(-) 10 \%$ and $(-) 50 \% \mathrm{CH}_{4} . \Delta p=4$ bar. Flow configuration: co-current (a and b) countercurrent (c and d),

The flow configuration has some influence on the carbon membrane for all methane feed concentrations. For counter-current flow, methane recovery is shifted towards higher membrane 
loadings, which means that a lower membrane area is needed for the same performance, if using this flow configuration. This positive effect of the counter-current flow is also observed for the concentration factor, which increases with respect to that obtained at co-current flow, but only for $1 \%$ and $10 \%$ methane feed concentrations.

In general, the positive effect of counter-current flow is more marked at high recoveries $(>60 \%)$ and low methane feed concentrations ( $\leq 10 \%)$. Otherwise, the curves for co-current and counter-current flow configurations almost overlap. Given that the carbon membrane is more suited to concentrate methane from rich feedstocks (i.e. methane feed concentration $\geq 50 \%$ ), the differences between both flow configurations at these conditions are minimal.

\subsection{Membrane design and scale-up}

\subsubsection{Selection of membrane module}

The membrane material is supported and arranged in membrane modules. The most common modules are hollow fiber and spiral-wound, with plate and frame being used in some applications. Hollow fiber modules contain a large number of membrane fibers with a very small diameter (0.5-2 $\mathrm{mm}$ ), housed inside a shell. The modules can be made in different sizes, with membrane areas in the range 0.05 to $5 \mathrm{~m}^{2}$ per module [39].

In this work, hollow fibre membrane modules have been chosen to support the studied membranes, because they are compact (provide large membrane area in small module volume). The selected module consists of cylindrical fibres of $2 \mathrm{~mm}$ diameter and $1.5 \mathrm{~m}$ length. The highest fibre diameter and lowest length are selected, within the recommended industrial standards, to minimize pressure drop. A fibre loading of 500 fibres per module is considered, which corresponds to a membrane area of $4.71 \mathrm{~m}^{2}$ per module [39].

\subsubsection{Membrane scale-up}

The membrane process will be scaled-up for two cases, corresponding to lean and rich methane feedstoks. In both cases, the same design specifications are used: feed gas flow rate of $1000 \mathrm{~m}^{3} / \mathrm{h}$ n.t.p. and methane recovery of $70 \%$.

The scale-up has been based on the model simulations and the results of the sensitivity analysis, carried out in the previous section. First, for a given membrane, feed concentration and methane recovery, Figure 7 or 8 are used to determine the required membrane loading $\left(F_{0} / A_{m}\right)$. Note that the information of these figures was obtained by simulation of the membrane and module models. Table 
1 presents a summary of the membrane loadings required under different scenarios for a methane recovery of $70 \%$. Finally, the membrane area is calculated from the required loading using the flow basis, $F_{0}=1000 \mathrm{~m}^{3} / \mathrm{h}$ n.t.p.

Table 1. Summary of membrane performance for $70 \%$ methane recovery and $\Delta p=4$ bar.

\begin{tabular}{llllll} 
& & \multicolumn{3}{l}{ Carbon } \\
\cline { 3 - 6 } $\begin{array}{llll}\text { Feed } \\
\text { concentration }\end{array}$ & Flow & $\mathrm{F}_{0} / \mathrm{A}_{\mathrm{m}}$ & $\begin{array}{l}\text { Conc. } \\
\left(\mathrm{mol} / \mathrm{m}^{2} \mathrm{~s}\right)\end{array}$ & $\begin{array}{l}\mathrm{F}_{0} / \mathrm{A}_{\mathrm{m}} \\
\left(\mathrm{moctor} / \mathrm{m}^{2} \mathrm{~s}\right)\end{array}$ & $\begin{array}{l}\text { Conc. } \\
\text { factor }\end{array}$ \\
\hline $1 \% \mathrm{CH}_{4}$ & configuration & 0.0614 & 6.3 & 0.0518 & 1.9 \\
& Co-current & 0.0633 & 5.2 & 0.0712 & 2.6 \\
$10 \% \mathrm{CH}_{4}$ & Counter-current & 0.0633 & 0.0595 & 1.9 \\
& Co-current & 0.0530 & 3.9 & 0.059 & 2.4 \\
$50 \% \mathrm{CH}_{4}$ & Counter-current & 0.0538 & 3.7 & 0.0797 & 1.6 \\
& Co-current & 0.0324 & 1.5 & 0.123 & 1.6 \\
\hline
\end{tabular}

\subsubsection{Case: lean methane feed}

The first case consists in a lean methane feedstock with a feed concentration of $1 \% \mathrm{CH}_{4}$. This low methane concentration is found in many waste streams that, in most situations, are emitted to the atmosphere without harnessing. For example, in coal mine ventilation air, water treatment plants, landfills and natural gas extraction and distribution systems, among others. The concentration of methane in these emissions using membranes would increase the harnessing possibilities, leading to a reduction of their environmental impact.

As discussed in Section 3.2, SAPO-34 membrane is best suited for lean methane sources, because it offers higher selectivity at low methane concentration. For this reason, this is the chosen membrane for the scale-up of the process in the case of a lean methane feed.

The sensitivity analysis carried out in the previous section indicated that the best operating conditions for SAPO-34 membrane are co-current flow configuration and transmembrane pressure difference of 4 bar. At these conditions, the membrane loading $F_{0} / A_{m}$ required to achieve a methane recovery of $70 \%$ is $0.0614 \mathrm{~mol} / \mathrm{m}^{2} \mathrm{~s}$, which is accompanied by a concentration factor of 6.32 (Table 1). According to these performance results, a retentate of $111 \mathrm{~m}^{3} / \mathrm{h}$ n.t.p. with $6.3 \% \mathrm{CH}_{4}$ and a permeate of $889 \mathrm{~m}^{3} / \mathrm{h}$ n.t.p. with $0.338 \% \mathrm{CH}_{4}$ are obtained. Noted that, in this membrane, methane concentrates in the retentate side.

The scale-up of the membrane process is done using the membrane loading at the abovementioned conditions, $F_{0} / A_{m}=0.0614 \mathrm{~mol} / \mathrm{m}^{2} \mathrm{~s}$. Thus, for a feed gas flow rate of $1000 \mathrm{~m}^{3} / \mathrm{h} \mathrm{n.t.p.,} \mathrm{the} \mathrm{total}$ 
membrane area required is $202 \mathrm{~m}^{2}$. This area is obtained using 43 membrane modules, each one of $4.71 \mathrm{~m}^{2}$, as indicated before in section 3.5.1.

\subsubsection{Case: rich methane feed}

The second case corresponds to a rich methane feedstock with a concentration of $50 \% \mathrm{CH}_{4}$. This is a completely different situation where the aim of the membrane process is to remove impurities and obtain a methane rich stream that can be used in regular combustion or chemical processes. Some methane feedstoks within this case are, for instance, coal bed methane, abandoned coal mine methane, stranded natural gas sources or air-diluted biogas generated in anaerobic biological processes (e.g. landfill biogas).

Table 1 shows the results of the sensitivity analysis corresponding to a methane recovery of $70 \%$ for SAPO-34 and carbon membranes. The concentration factor is practically the same for both membranes (in the range 1.5 to 1.6). This means that the outlet streams of both membranes have the same flow rate and concentration. However, methane is concentrated in different outlet streams for this pair of membranes. The retentate of the SAPO-34 membrane and the permeate of the carbon one have a flow rate of $438 \mathrm{~m}^{3} / \mathrm{h}$ n.t.p. with $80.0 \% \mathrm{CH}_{4}$, while the permeate of the SAPO-34 membrane and the retentate of the carbon one have a flow rate of $562 \mathrm{~m}^{3} / \mathrm{h}$ n.t.p. with $26.7 \% \mathrm{CH}_{4}$. Given the previous performance, the considered membranes are able of increasing methane concentration from $50 \%$ to $80 \%$.

The selection of the best membrane material for the separation proposed in this case has been made considering the membrane area needed to achieve abovementioned performance. For the SAPO-34 membrane, a membrane loading of $F_{0} / A_{m}=0.0324 \mathrm{~mol} / \mathrm{m}^{2} \mathrm{~s}$ is required $(\Delta p=4$ bar and co-current flow), which leads to a membrane area of $383 \mathrm{~m}^{2}$. The carbon membrane has the same performance with a membrane loading of $F_{0} / A_{m}=0.123 \mathrm{~mol} / \mathrm{m}^{2}(\Delta p=4$ bar and co-current flow). Hence, the membrane area needed is reduced to $101 \mathrm{~m}^{2}$. At counter-current flow, this membrane is slightly more efficient and the membrane area is reduced a bit more to $96 \mathrm{~m}^{2}$. The latter value is traduced into 20 membrane modules, each of $4.71 \mathrm{~m}^{2}$ area.

\subsubsection{Green house gas emissions assessment}

The use of the designed membrane modules requires the compression of the feed to 5 bar (design transmembrane pressure difference was 4 bar). This compression produces an emission of greenhouse gases that should be considered to assess the impact of the membrane process. Thus, 
for a feed gas flow rate of $1000 \mathrm{~m}^{3} / \mathrm{h}$ n.t.p. (design basis), the brake power required in a 2-stage centrifugal compressor is $82 \mathrm{~kW}$ (considering 70\% polytrophic and 93\% mechanical efficiencies) [40]. This electrical power can be traduced into greenhouse gas emissions using the methodology proposed by the Intergovernmental Panel on Climate Change (IPCC) on their 2014 report [41]. Depending on the power source, different impacts in term of lifecycle emissions are produced, for example, $490 \mathrm{~g} \mathrm{CO}_{2}$-eq/kWh for the case of natural gas-based power sources and $11 \mathrm{~g} \mathrm{CO}_{2}$-eq/ $\mathrm{kWh}$ for wind or nuclear power sources. As a simplification, a power generation scheme formed by $50 \%$ natural gas and $50 \%$ wind/nuclear is considered, resulting in an impact of $21 \mathrm{~kg} \mathrm{CO}$-eq $/ \mathrm{h}$ for the compressor operation.

The use of membranes to concentrate methane from lean feedstocks may broad the harnessing possibilities of these feedstocks that, otherwise, would be emitted to the atmosphere. Since methane is a powerful greenhouse gas with a global warming potential of $28 \mathrm{~kg} \mathrm{CO}$-eq (100-year basis) [42], the combustion of methane from these emissions to $\mathrm{CO}_{2}$ has a net positive environmental impact, apart from the heat and power generated. In this work, a membrane process has been designed to concentrate a lean feed of $1000 \mathrm{~m}^{3} / \mathrm{h}$ n.t.p. from $1 \%$ to $6.3 \%$ methane with a recovery of $70 \%$. Using these figures, the emission to the atmosphere of $140 \mathrm{~kg} \mathrm{CO}$-eq $/ \mathrm{h}$ is avoided. Given that the required gas compression produces an impact of $21 \mathrm{~kg} \mathrm{CO}_{2}$-eq $/ \mathrm{h}$, it can be concluded that the membrane system contributes with a net impact reduction of $119 \mathrm{~kg} \mathrm{CO}_{2}$-eq $/ \mathrm{h}$.

\section{Conclusions}

Some methane feedstocks contain important amounts of nitrogen, which limits the harnessing possibilities. In this work, the concentration of methane from these feedstocks is addressed by the use of membrane separation techniques, i.e. gas permeation. Mass transfer in two microporous membrane materials, SAPO-34 and porous carbon, has been modelled using the Maxwell-Stefan multicomponent surface diffusion model. The model performance has been validated using the limited literature data available for this type of mixtures. The application of this model has been extended by simulating the concentration profiles along the length of the membrane module using the plug flow model.

A sensitivity analysis of the main variables affecting the performance of the membrane (transmembrane pressure difference, flow configuration in the module, methane feed concentration and membrane loading, $F_{0} / A_{m}$ ) has been carried out. The main variables to take into account for the design and scale-up of the operation are transmembrane pressure difference, methane feed concentration and membrane loading. The results have revealed that both membranes are able of 
concentrating methane; however, it has been found that SAPO-34 membranes are more suited to concentrate methane in lean mixtures, while the carbon membrane perform better with rich mixtures.

According to these results, two membrane units have been scaled-up, respectively, for lean (1\%) and rich (50\%) methane feed mixtures. Both units consider the same design basis: feed gas flow rate of $1000 \mathrm{~m}^{3} / \mathrm{h}$ n.t.p. and $70 \%$ methane recovery. For the case of lean methane mixtures, the SAPO-34 membrane is able of concentrating methane from $1 \%$ to $6.3 \%$ using $202 \mathrm{~m}^{2}$ of membrane area and 4 bar of transmembrane pressure difference. For the case of rich methane mixtures, the carbon membrane is able of concentrating methane from $50 \%$ to $80 \%$ using $101 \mathrm{~m}^{2}$ of membrane area and 4 bar of transmembrane pressure difference.

\section{Acknowledgements}

This work has been financed by the Research Fund for Coal and Steel of the European Union (contract RFCS2016/754077-METHENERGY+). 


\section{List of symbols}

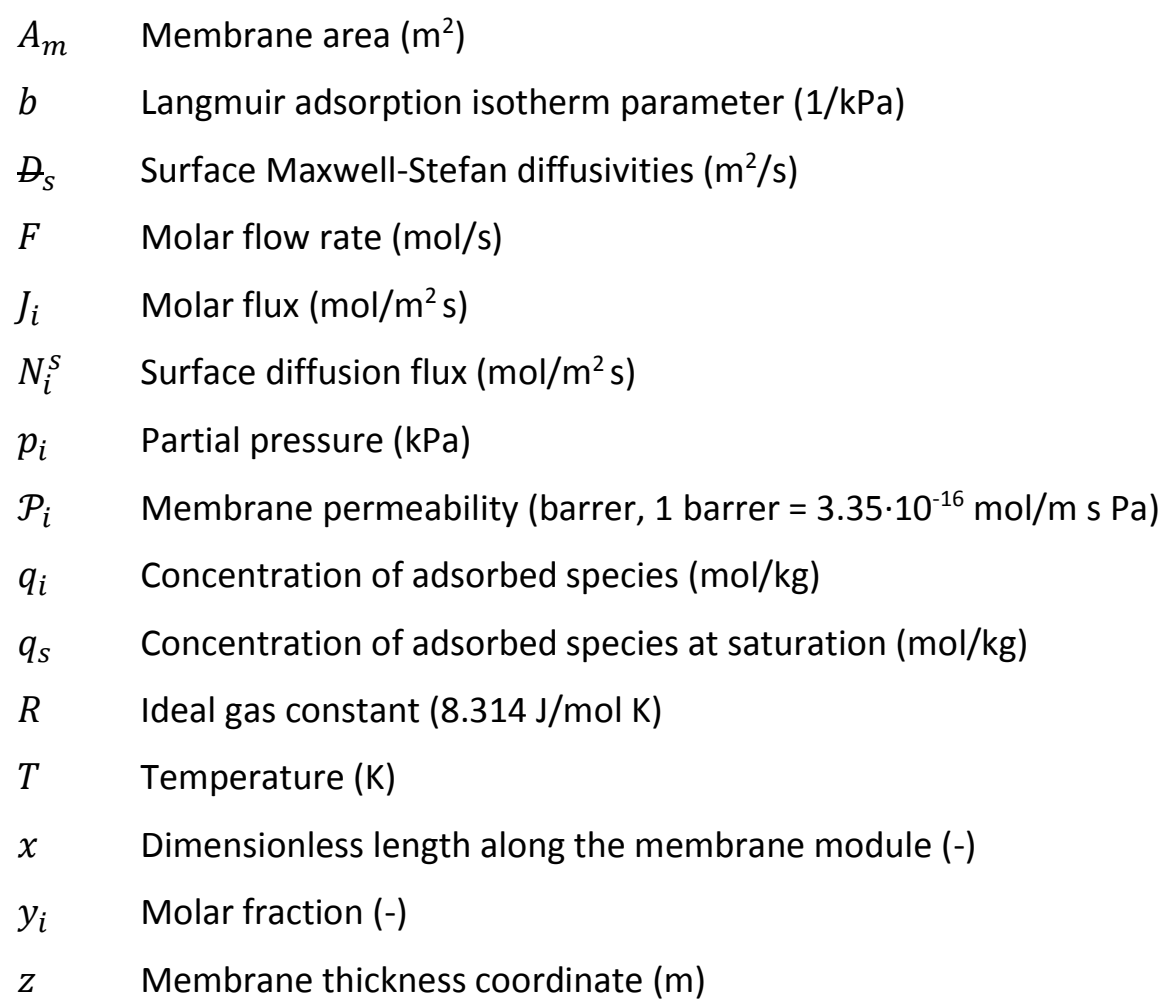

\section{Greek symbols}

$\delta \quad$ Thickness of the membrane active layer $(\mathrm{m})$

$\Delta H_{\text {ads }}$ Adsorption enthalpy $(\mathrm{kJ} / \mathrm{mol})$

$\Delta p \quad$ Transmembrane pressure difference (bar)

$\theta_{i} \quad$ Fractional surface coverage (-)

$\Gamma_{i j} \quad$ Maxwell-Stefan thermodynamic factors (-)

$\mu_{i} \quad$ Surface chemical potential $(\mathrm{J} / \mathrm{mol})$

$\Pi_{i} \quad$ Membrane permeance (GPU, gas permeance unit, $1 \mathrm{GPU}=3.35 \cdot 10^{-10} \mathrm{~mol} / \mathrm{m}^{2} \mathrm{~s} \mathrm{~Pa}$ )

$\rho_{S} \quad$ Solid density $\left(\mathrm{kg} / \mathrm{m}^{3}\right)$

\section{Subscripts}

$0 \quad$ Feed

$P \quad$ Permeate

$R \quad$ Retentate

sw Sweep gas 


\section{References}

[1] M. Saunois, R.B. Jackson, P. Bousquet, B. Poulter, J.G. Canadell, The growing role of methane in anthropogenic climate change, Environ. Res. Lett., 11 (2016) 5.

[2] M. Álvarez, P. Marín, S. Ordóñez, Direct oxidation of methane to methanol over Cu-zeolites at mild conditions, Molecular Catalysis, 487 (2020) 110886.

[3] D. Li, R. Xu, Z. Gu, X. Zhu, S. Qing, K. Li, Chemical-Looping Conversion of Methane: A Review, Energy Technology, (2019) 1900925.

[4] P. Marín, F.V. Díez, S. Ordóñez, Reverse flow reactors as sustainable devices for performing exothermic reactions: Applications and engineering aspects, Chemical Engineering and Processing Process Intensification, 135 (2019) 175-189.

[5] A. Setiawan, E.M. Kennedy, M. Stockenhuber, Development of Combustion Technology for Methane Emitted from Coal-Mine Ventilation Air Systems, Energy Technology, 5 (2017) 521-538.

[6] C.J. Bibler, J.S. Marshall, R.C. Pilcher, Status of worldwide coal mine methane emissions and use, International Journal of Coal Geology, 35 (1998) 283-310.

[7] M.A. Carreon, Molecular sieve membranes for $\mathrm{N}_{2} / \mathrm{CH}_{4}$ separation, Journal of Materials Research, (2017) 1-12.

[8] F.M. Baena-Moreno, M. Rodríguez-Galán, F. Vega, L.F. Vilches, B. Navarrete, Z. Zhang, Biogas upgrading by cryogenic techniques, Environmental Chemistry Letters, 17 (2019) 1251-1261.

[9] H. Liu, W. Ding, F. Zhou, G. Yang, Y. Du, An overview and outlook on gas adsorption: for the enrichment of low concentration coalbed methane, Separation Science and Technology

(Philadelphia), 55 (2020) 1102-1114.

[10] H.R. Sant Anna, A.G. Barreto, F.W. Tavares, J.F. do Nascimento, Methane/nitrogen separation through pressure swing adsorption process from nitrogen-rich streams, Chemical Engineering and Processing: Process Intensification, 103 (2016) 70-79.

[11] K. Warmuziński, W. Sodzawiczny, Effect of adsorption pressure on methane purity during PSA separations of $\mathrm{CH}_{4} / \mathrm{N}_{2}$ mixtures, Chemical Engineering and Processing: Process Intensification, 38 (1999) 55-60.

[12] P. Zhao, G. Zhang, Y. Sun, Y. Xu, A review of oxygen removal from oxygen-bearing coal-mine methane, Environmental Science and Pollution Research, 24 (2017) 15240-15253.

[13] J.C. Kuo, K.H. Wang, C. Chen, Pros and cons of different Nitrogen Removal Unit (NRU) technology, Journal of Natural Gas Science and Engineering, 7 (2012) 52-59.

[14] D. Ko, Development of a dynamic simulation model of a hollow fiber membrane module to sequester $\mathrm{CO}_{2}$ from coalbed methane, Journal of Membrane Science, 546 (2018) 258-269.

[15] S. Li, M.A. Carreon, Y. Zhang, H.H. Funke, R.D. Noble, J.L. Falconer, Scale-up of SAPO-34 membranes for $\mathrm{CO}_{2} / \mathrm{CH}_{4}$ separation, Journal of Membrane Science, 352 (2010) 7-13.

[16] Y. Yampolskii, N. Belov, A. Alentiev, Perfluorinated polymers as materials of membranes for gas and vapor separation, Journal of Membrane Science, 598 (2020) 117779.

[17] K.A. Lokhandwala, I. Pinnau, Z. He, K.D. Amo, A.R. DaCosta, J.G. Wijmans, R.W. Baker, Membrane separation of nitrogen from natural gas: A case study from membrane synthesis to commercial deployment, Journal of Membrane Science, 346 (2010) 270-279.

[18] C.A. Scholes, G.W. Stevens, S.E. Kentish, Membrane gas separation applications in natural gas processing, Fuel, 96 (2012) 15-28.

[19] P.F. Lito, S.P. Cardoso, A.E. Rodrigues, C.M. Silva, Kinetic Modeling of Pure and Multicomponent Gas Permeation Through Microporous Membranes: Diffusion Mechanisms and Influence of Isotherm Type, Separation \& Purification Reviews, 44 (2015) 283-307.

[20] X. Ning, W.J. Koros, Carbon molecular sieve membranes derived from Matrimid ${ }^{\circledR}$ polyimide for nitrogen/methane separation, Carbon, 66 (2014) 511-522.

[21] W. Jiao, Y. Ban, Z. Shi, X. Jiang, Y. Li, W. Yang, High performance carbon molecular sieving membranes derived from pyrolysis of metal-organic framework ZIF-108 doped polyimide matrices, Chemical Communications, 52 (2016) 13779-13782. 
[22] S.S. Hosseini, T.S. Chung, Carbon membranes from blends of $\mathrm{PBI}$ and polyimides for $\mathrm{N}_{2} / \mathrm{CH}_{4}$ and $\mathrm{CO}_{2} / \mathrm{CH}_{4}$ separation and hydrogen purification, Journal of Membrane Science, 328 (2009) 174-185.

[23] M.B. Rao, S. Sircar, Nanoporous carbon membrane for gas separation, Gas Separation \& Purification, 7 (1993) 279-284.

[24] S. Li, Z. Zong, S.J. Zhou, Y. Huang, Z. Song, X. Feng, R. Zhou, H.S. Meyer, M. Yu, M.A. Carreon, SAPO-34 Membranes for $\mathrm{N}_{2} / \mathrm{CH}_{4}$ separation: Preparation, characterization, separation performance and economic evaluation, Journal of Membrane Science, 487 (2015) 141-151.

[25] T. Wu, M.C. Diaz, Y. Zheng, R. Zhou, H.H. Funke, J.L. Falconer, R.D. Noble, Influence of propane on $\mathrm{CO}_{2} / \mathrm{CH}_{4}$ and $\mathrm{N}_{2} / \mathrm{CH}_{4}$ separations in $\mathrm{CHA}$ zeolite membranes, Journal of Membrane Science, 473 (2015) 201-209.

[26] S.F. Alam, M.-Z. Kim, Y.J. Kim, A.u. Rehman, A. Devipriyanka, P. Sharma, J.-G. Yeo, J.-S. Lee, H. $\mathrm{Kim}, \mathrm{C}$.-H. Cho, A new seeding method, dry rolling applied to synthesize SAPO-34 zeolite membrane for nitrogen/methane separation, Journal of Membrane Science, 602 (2020) 117825.

[27] J.C. Poshusta, V.A. Tuan, J.L. Falconer, R.D. Noble, Synthesis and Permeation Properties of SAPO34 Tubular Membranes, Industrial \& Engineering Chemistry Research, 37 (1998) 3924-3929.

[28] S. Li, J.L. Falconer, R.D. Noble, R. Krishna, Modeling Permeation of $\mathrm{CO}_{2} / \mathrm{CH}_{4}, \mathrm{CO}_{2} / \mathrm{N}_{2}$, and $\mathrm{N}_{2} / \mathrm{CH}_{4}$ Mixtures Across SAPO-34 Membrane with the Maxwell-Stefan Equations, Industrial \& Engineering Chemistry Research, 46 (2007) 3904-3911.

[29] J. van den Bergh, W. Zhu, J. Gascon, J.A. Moulijn, F. Kapteijn, Separation and permeation characteristics of a DD3R zeolite membrane, Journal of Membrane Science, 316 (2008) 35-45.

[30] B.R. Pimentel, A. Parulkar, E.-k. Zhou, N.A. Brunelli, R.P. Lively, Zeolitic Imidazolate Frameworks: Next-Generation Materials for Energy-Efficient Gas Separations, ChemSusChem, 7 (2014) 3202-3240.

[31] B. Chen, Z. Yang, Y. Zhu, Y. Xia, Zeolitic imidazolate framework materials: recent progress in synthesis and applications, Journal of Materials Chemistry A, 2 (2014) 16811-16831.

[32] C. Chen, A. Ozcan, A.O. Yazaydin, B.P. Ladewig, Gas permeation through single-crystal ZIF-8 membranes, Journal of Membrane Science, 575 (2019) 209-216.

[33] G. Xu, J. Yao, K. Wang, L. He, P.A. Webley, C.-s. Chen, H. Wang, Preparation of ZIF-8 membranes supported on ceramic hollow fibers from a concentrated synthesis gel, Journal of Membrane Science, 385-386 (2011) 187-193.

[34] R. Krishna, J.A. Wesselingh, The Maxwell-Stefan approach to mass transfer, Chemical Engineering Science, 52 (1997) 861-911.

[35] L.J.P. Van Den Broeke, R. Krishna, Experimental verification of the Maxwell-Stefan theory for micropore diffusion, Chemical Engineering Science, 50 (1995) 2507-2522.

[36] R. Krishna, J.M. van Baten, Maxwell-Stefan modeling of slowing-down effects in mixed gas permeation across porous membranes, Journal of Membrane Science, 383 (2011) 289-300.

[37] M. Ahsan, A. Hussain, Mathematical modelling of membrane gas separation using the finite difference method, Pacific Science Review A: Natural Science and Engineering, 18 (2016) 47-52.

[38] B. Haddadi, C. Jordan, M. Miltner, M. Harasek, Membrane modeling using CFD: Combined evaluation of mass transfer and geometrical influences in 1D and 3D, Journal of Membrane Science, 563 (2018) 199-209.

[39] Y. Yampolskii, B. Freeman, Membrane gas separation, John Wiley \& Sons Ltd, 2010.

[40] C. Branan, Rules of Thumb for Chemical Engineers, 4th ed., Elsevier, 2008.

[41] S. Schlömer, T. Bruckner, L. Fulton, E. Hertwich, A. McKinnon, D. Perczyk, J. Roy, R. Schaeffer, R. Sims, P. Smith, R. Wiser, Annex III: Technology-specific cost and performance parameters, in: Climate Change 2014: Mitigation of Climate Change. Contribution of Working Group III to the Fifth

Assessment Report of the Intergovernmental Panel on Climate Change, Cambridge University Press, 2014.

[42] G. Myhre, D. Shindell, F.-M. Bréon, W. Collins, J. Fuglestvedt, J. Huang, D. Koch, J.-F. Lamarque, D. Lee, B. Mendoza, T. Nakajima, A. Robock, G. Stephens, T. Takemura, H. Zhang, Anthropogenic and Natural Radiative Forcing, in: Climate Change 2013: The Physical Science Basis. 5th Assessment Report of the Intergovernmental Panel on Climate Change (IPCC), Cambridge University Press, Cambridge, United Kingdom and New York, NY, USA., 2013. 